\title{
Community harvesting of trees used as dens and for food by the tree hyrax (Dendrohyrax arboreus) in the Pirie forest, South Africa
}

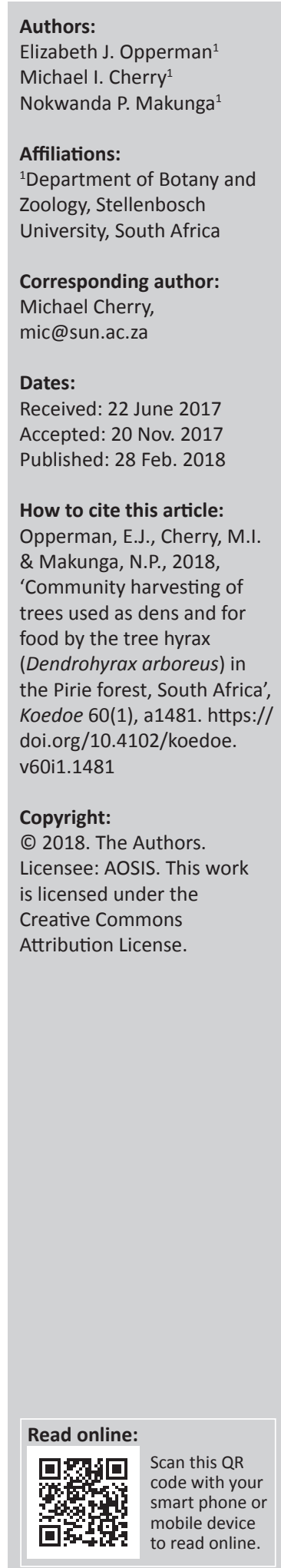

Forests in South Africa are harvested by local communities for multiple purposes and this affects the animals that inhabit them. The tree hyrax (Dendrohyrax arboreus) has a restricted distribution and utilises various tree species as dens and a source of food. In this article, we determined, through a series of interviews in the communities surrounding the Pirie forest, which plant species are harvested by local people and whether these overlap with those used by the tree hyrax. In addition, we determined the extent to which tree hyraxes are hunted by these communities. Of the trees used by the hyrax as dens in the Pirie forest, Afrocarpus falcatus, Schotia latifolia, Andrachne ovalis, Teclea natalensis and Apodytes dimidiata are important resources for local communities. But as these are harvested at relatively low levels, it is unlikely that current harvesting has a large impact on the tree hyrax. Opportunistic hunting occurs, but the hyrax is not targeted by hunters. Very limited commercial harvesting of $A$. falcatus has been taking place in the Pirie forest since 1975, but its impact on the hyrax population, although undetermined, is also unlikely to be high. We recommend that the Pirie forest tree hyrax population should be monitored by forest management in order to ascertain the impact of both commercial and community harvesting over the past quarter century.

Conservation implications: Tree hyrax populations in the Pirie forest should be actively monitored by management on an annual basis.

\section{Introduction}

The world's forests have experienced high levels of destruction (owing to deforestation) and degradation (owing to unsustainable harvesting). In South Africa, indigenous forests cover only $0.56 \%$ of the land surface (Low \& Rebelo 1996), but these forests have a long history of exploitation. Timber harvesting, in particular, increased between 1890 and 1940 but has since declined owing to increased use of alien vegetation for timber used in construction (Brown 2003; Cunningham \& Davis 1997; Lawes, Midgley \& Chapman 2004). However, many forests are harvested by proximate local communities which are dependent on forests as a source of food, medicine and timber for both household consumption and income; harvesting also forms an integral part of the culture of these communities (Dold \& Cocks 2012). As South Africa has very little forest cover, forest-specialised species are restricted to relatively few forests, which in many cases are subject to extensive human exploitation (Castley \& Kerley 1996). In forests exploited by humans, the forest biota is clearly affected. For example, Cooper, Wannenburgh and Cherry (2017) have found that half of South Africa's forest-dependent bird species have declined over the past quarter century, particularly in the Eastern Cape forests, despite the fact that the forests have not decreased in area.

The tree hyrax (Dendrohyrax arboreus) is an arboreal, nocturnal and folivorous small mammal with a disjunct distribution across southern and eastern Africa (see Figure 1 in Gaylard et al. 2016). The tree hyrax uses the hollows of trees for their dens and prefers hollow, large, upright and dying trees with many cavity entrances (Gaylard \& Kerley 2001). In South Africa, it is confined to relatively few forests in the Eastern Cape and KwaZulu-Natal: it is estimated that only $1 \%$ of its former range in South Africa, Lesotho and Swaziland is currently occupied (Gaylard et al. 2016). Interestingly, different tree species are used as dens and for foraging in the coastal forests of Alexandria and Springmount as opposed to the Afromontane mistbelt Pirie forests (Gaylard \& Kerley 1997, 2001). Although the tree hyrax is listed as of least concern by the International Union for Conservation of Nature (IUCN), the listing mentions that as the southern and eastern African forests are under threat, the situation needs to be monitored (Butynski, Hoeck \& De Jong 2015). The local red listing is endangered (Gaylard et al. 2016). 
This study focused on community harvesting of trees in the vicinity of the Pirie forest (Figure 1), which forms part of the Amatole mistbelt forests in the Eastern Cape province of South Africa, and the possible threat it poses to the forest's tree hyrax populations. In the Pirie forest, the hyrax utilises only six tree species as dens: Searsia chirindensis (Red currant), Schotia latifolia (Forest boerboon), Andrachne ovalis (Bastard lightning bush), Apodytes dimidiata (White pear), Afrocarpus falcatus (Outeniqua yellowwood) and Teclea natalensis (Small-fruited teclea) (Gaylard \& Kerley 2001). By contrast, tree hyraxes have been recorded as foraging on the leaves of 36 different plant species in the Pirie forest (Gaylard \& Kerley 1997).

The Pirie forest is one of only two forests nationally (the other is the Knysna forest) where commercial harvesting is permitted by the Department of Agriculture, Forestry and Fisheries (DAFF) for two yellowwood species, A. falcatus and Podocarpus latifolius (Real yellowwood) (Mpisekaya \& Kameni 2007). The former is one of the species in the Pirie forest used as a den by the hyrax (Gaylard \& Kerley 2001). Although harvesting is permitted only of trees which are dead or dying, are wind fallen or have lost their crowns, this may still have an impact on the hyrax as they depend on dead or dying trees with hollows for their dens (Lawes, Mealin \& Piper 2000). Commercial wood harvesting in the Amatole forests was once again permitted from 1975 onwards, having been terminated in 1940 (Mpisekaya \& Kameni 2007). Since 2007, harvesting has been limited to $0.1 \%$ of available stems of these species per annum. Indiscriminate historical harvesting may explain why hyraxes occur at a low density in the Pirie forest, in contrast to the Springmount forest, a drier dune forest where it occurs at higher densities (Gaylard 1994). But as A. falcatus comprised only $14.3 \%$ of the trees used by the hyrax as dens in the Pirie forest in 1992, despite it being a dominant species there (Gaylard \& Kerley 2001; Greyling \& Huntley 1984), it is unlikely that current levels of commercial harvesting impact negatively tree hyrax numbers.

The Pirie forest was chosen as a study site because of its proximity to villages, and the fact that like most forests protected by DAFF, it is not fenced and so can be easily accessed. In addition to commercial harvesting, local community members are officially allowed to take only a daily head-load (inyanda in isiXhosa but popularly referred to as theza) of wood lying on the ground, intended primarily for use as firewood, which should have no impact on the hyrax (J. Feely [Nelson Mandela Metropolitan University, Port Elizabeth] pers. comm., 01 October 2015). Despite this, illegal harvesting of bark for spiritual and medicinal purposes, as well as cutting trees for poles for building material, is widespread in Eastern Cape forests (Dold \& Cocks 2012). The former can result in ring-barking of trees, and cutting of trees for poles can result in canopy reduction, both of which could negatively affect the tree hyrax. In addition, illegal hunting of small game with dogs is also an important pastime among young men and boys (Dold \& Cocks 2012).
In this study, we used a series of semi-structured interviews in the communities surrounding the Pirie forest in order to determine the plant species harvested by the local communities. In addition, we aimed to gauge the extent of harvesting in the Pirie forest and for what purposes harvested material is used. We also aimed to determine the extent to which hunting for tree hyrax takes place in the forest and whether communities living around the Pirie forest were aware of the tree hyrax and, if so, knew anything about its behaviour. We predicted that harvested tree species would overlap with those utilised by the hyrax as den and food sources described in Gaylard and Kerley (2001).

\section{Methods}

The study was conducted in seven randomly selected communities in close proximity to the Pirie forest in the Eastern Cape of South Africa in July 2015 (Figure 1). The Pirie forest $\left(32^{\circ} 43^{\prime} \mathrm{S}, 2^{\circ} 16^{\prime} \mathrm{E}\right)$ is situated between Keiskammahoek and King Williams Town at an altitude between $540 \mathrm{~m}$ and $1300 \mathrm{~m}$, is 3173 ha in extent and has a stand density of 2115.6 stems/ha (Von Maltitz et al. 2003). The area has a very steep sloping pediment with cliffs as well as several rock faces, and the major river running through it is the Buffalo River (Greyling \& Huntley 1984). Interviews were conducted in the villages of Pirie Mission (32 $\left.47^{\prime} 33.03^{\prime \prime} \mathrm{S}, 27^{\circ} 14^{\prime} 54.86^{\prime \prime} \mathrm{E}\right)$, Cwengcwe (3246'15.91"S, $\left.27^{\circ} 20^{\prime} 38.47^{\prime \prime} \mathrm{E}\right), \quad$ Mxhalanga (32 $\left.44^{\prime} 1.37^{\prime \prime} \mathrm{S}, 27^{\circ} 21^{\prime} 31.35^{\prime \prime} \mathrm{E}\right)$, Tyusha $\left(32^{\circ} 41^{\prime} 51.01^{\prime \prime S}, \quad 27^{\circ} 22^{\prime} 16.30^{\prime \prime} \mathrm{E}\right), \quad$ New Rest

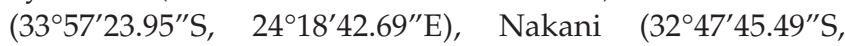
$\left.27^{\circ} 13^{\prime} 5.51^{\prime \prime} \mathrm{E}\right)$ and Gubevu (32 $\left.5^{\prime} 6.00^{\prime \prime S}, \quad 28^{\circ} 23^{\prime} 9.00^{\prime \prime} \mathrm{E}\right)$ (Google Earth 2013).

At each village, the village leader or chief was asked for permission to conduct interviews in the community. The leaders, who were informed of the purpose of the survey as well as the rights of each participant, assisted in identifying known harvesters and those who hunt animals within the forest. Semi-structured questionnaires (Appendix 1) were used to determine which tree species are used, and to what extent and purpose. Participants were identified by a snowballing or referral technique in which the person interviewed provided possible future participants, based on existing connections within the community.

The purpose of the study and the rights of the participants were explained to each participant in isiXhosa before the interview was undertaken. Each participant was also asked to sign a consent form. Anonymity of participants was guaranteed in terms of reporting results from the study. But as harvesters and hunters may be reluctant to share information openly, our results should be regarded as reporting minimum levels of both activities. One of the interviews was conducted in English, and the rest in isiXhosa with the help of a translator. Answers were noted down and one of the interviews was recorded after consent from the participant was obtained. A total of 28 people were interviewed, who were asked basic biographical information plus whether they harvest, which species they harvest, how 


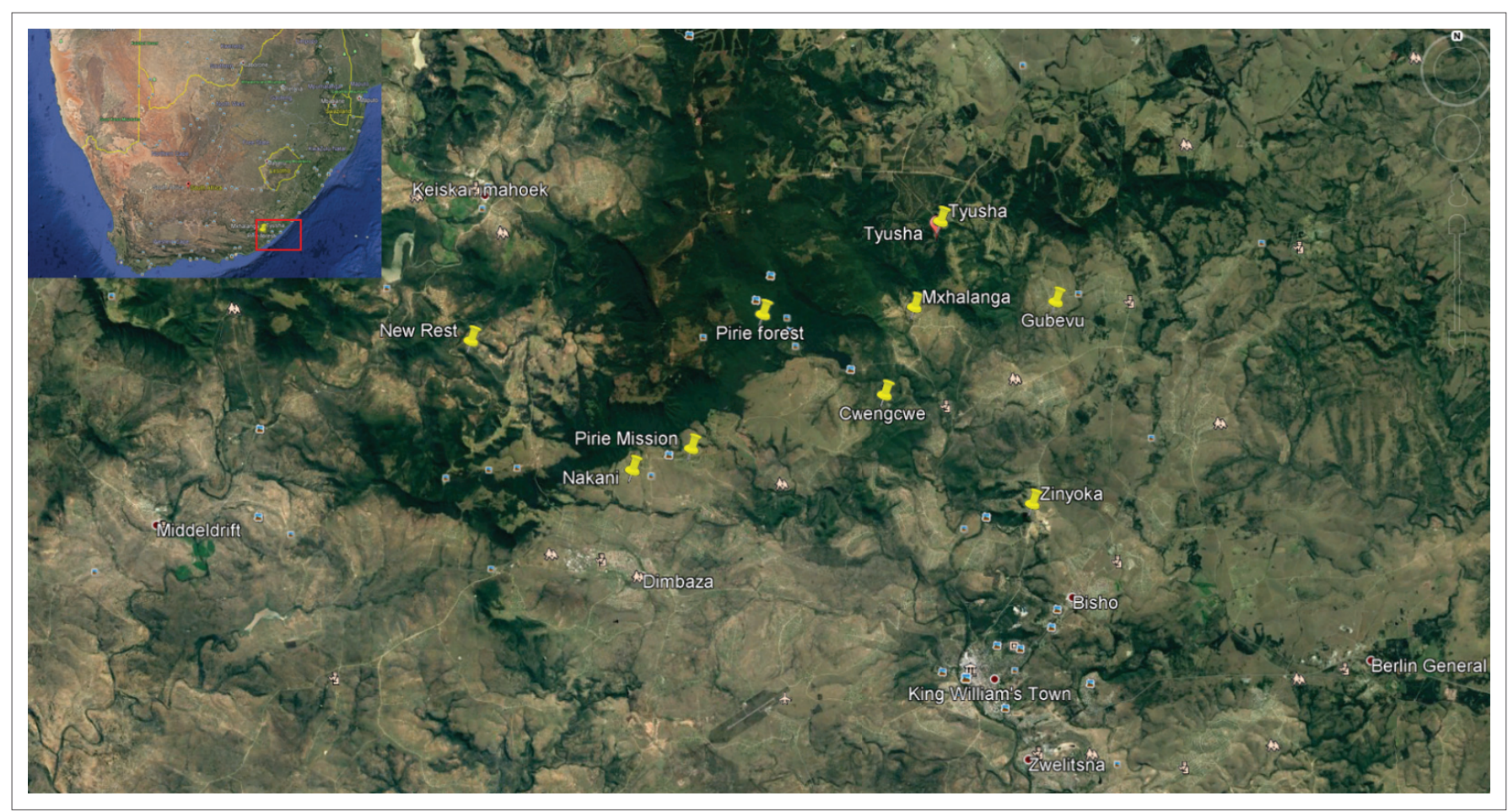

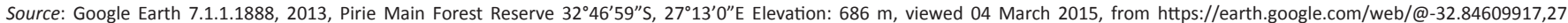
47770818,506.94577214a,77550.7433243d,35y,0.00000009h, 2.62787946t,-Or/data=CksaSRJDCiUweDFINjZIMTE2ZDVkOWQ3YjU6MHg5ZTFjMWE0NjQzNDRmNThm\GR5CpsaVgkDAIY50BkZe3 DtAKghOZXcgUmVzdBgBIAE

FIGURE 1: Map showing the Pirie forest and the locations of the villages in which the interviews were conducted. The yellow pins represent the communities in this study.

much they harvest and how often they harvest. In addition, they were asked about hunting practices surrounding the hyrax, and general knowledge of the hyrax. The questionnaire consisted of multi-choice and open-ended questions. The sample comprised 20 men and 8 women. The participants interviewed were evenly spread across age classes (Table 1); the majority of the participants earned less than R500 per month and had an education lower than Grade 7.

A list of all the plants harvested by the participants was made, and the isiXhosa vernacular names were translated into scientific names using Dold and Cocks (1999). The relative frequency of citation (RFC) for each plant species was determined. The RFC can be used to estimate the local importance of a certain plant species based on the number of times it was mentioned and is calculated using the equation:

$\mathrm{RFC}=\mathrm{FC} / \mathrm{N}$

[Eqn 1]

where $\mathrm{RFC}=$ relative frequency of citation, $\mathrm{FC}=$ number of participants mentioning the use of the species and $\mathrm{N}=$ number of participants taking part in the survey (Samoisy \& Mahomoodally 2015).

The perceptions of local people, distilled from open-ended interviews, were also documented qualitatively.

\section{Results}

Of the six tree species used by the hyrax for both dens and forage, the participants reported harvesting of five:
TABLE 1: The demographics of the participants interviewed at the Pirie forest, South Africa.

\begin{tabular}{|c|c|c|c|}
\hline Demographic & Classes & $\begin{array}{l}\text { Number of } \\
\text { individuals }\end{array}$ & $\begin{array}{c}\text { Percentage of } \\
\text { individuals }\end{array}$ \\
\hline \multirow[t]{2}{*}{ Gender } & Male & 20 & 71.43 \\
\hline & Female & 8 & 28.57 \\
\hline \multirow[t]{6}{*}{ Age } & $18-29$ & 5 & 17.86 \\
\hline & $30-39$ & 5 & 17.86 \\
\hline & $40-49$ & 5 & 17.86 \\
\hline & $50-59$ & 5 & 17.86 \\
\hline & $60-69$ & 4 & 14.29 \\
\hline & $70+$ & 4 & 14.29 \\
\hline \multirow[t]{8}{*}{ Villages } & Pirie Mission & 5 & 17.86 \\
\hline & Cwengcwe & 2 & 7.14 \\
\hline & Mxhalanga & 3 & 10.71 \\
\hline & Tyusha & 8 & 28.57 \\
\hline & Newrest & 3 & 10.71 \\
\hline & Nakani & 3 & 10.71 \\
\hline & Gubevu & 2 & 7.14 \\
\hline & King Williams Town & 2 & 7.14 \\
\hline \multirow[t]{5}{*}{ Monthly income } & $<$ R500 & 19 & 67.86 \\
\hline & R500-R1000 & 2 & 7.14 \\
\hline & R1000-R3000 & 6 & 21.43 \\
\hline & R3000-R10 000 & 1 & 3.57 \\
\hline & $>$ R10 000 & 0 & 0.00 \\
\hline \multirow[t]{4}{*}{ Education } & Grade 7 or below & 14 & 50.00 \\
\hline & Grade 10 & 2 & 7.14 \\
\hline & Matric & 4 & 14.29 \\
\hline & More & 2 & 7.14 \\
\hline
\end{tabular}

S. latifolia, T. natalensis, A.falcatus, And.ovalis and Apo. Dimidiata. Of these, A. falcatus and $S$. latifolia had the highest RFC values (Figure 2). Of the respondents, 57\% harvested, 22\% harvested and hunted, $7 \%$ hunted and the remaining $14 \%$ did neither but 
had general knowledge of harvesting practices in the area (Figure 3a). Of the harvesters, 36\% reported doing so only for personal use; the remaining $64 \%$ did so both for personal use and selling. Regarding frequency of harvesting, only $7 \%$ harvested daily, with most participants reporting that the frequency of harvesting depends either on what they need or that they harvest only every few months or on a monthly basis (Figure $3 b$ ). Of the 12 respondents who were able to estimate quantities harvested, 25\% reported harvesting less than $1 \mathrm{~kg}$ per month; 25\% between $1 \mathrm{~kg}$ and $50 \mathrm{~kg}$; and just under $17 \%$ reported harvesting in each of the categories, namely $50 \mathrm{~kg}-100 \mathrm{~kg}, 100 \mathrm{~kg}-200 \mathrm{~kg}$ and over $200 \mathrm{~kg}$ per month.

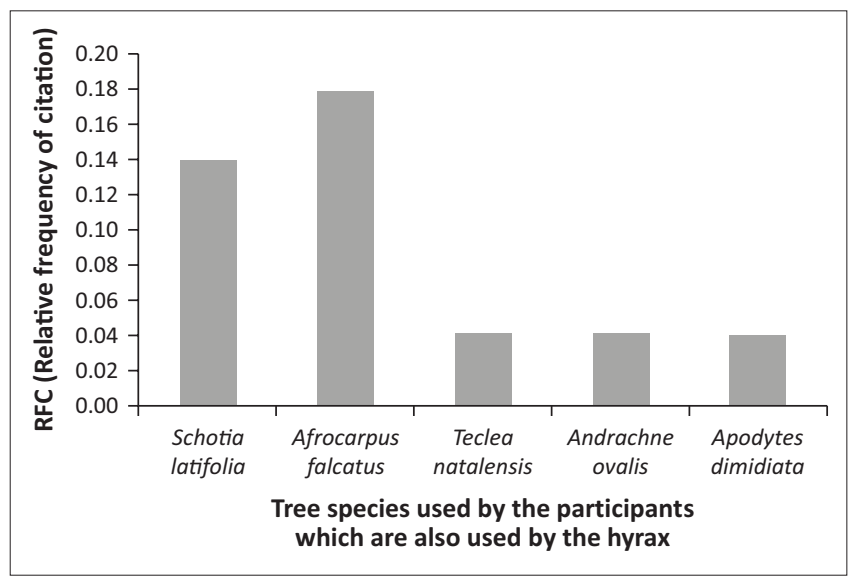

Source: Compiled by authors based on Gaylard, A. \& Kerley, G.I.H., 2001, 'Habitat assessment for a rare, arboreal forest mammal, the tree hyrax Dendrohyrax arboreus', African Journal of Ecology 39, 205-212. https://doi.org/10.1046/j.0141-6707.2000.301.x

FIGURE 2: Relative frequency of citation of tree species harvested near the Pirie forest which are used as dens by the tree hyrax.
The participants mentioned that the bark of the plants was used most (Figure 3c), followed by the stems, leaves, branches and lastly the roots and/or tubers. Most participants said that the products they harvest are used for medicinal purposes, followed by firewood, building material and customs and traditions (Figure 3d), including the passage of boys to manhood and ancestral worship ceremonies.

A total of 42 plant species was reported to be harvested. The alien Acacia mearnsii (Black wattle) and Ptaeroxylon obliquum (Sneezewood) were mentioned most by participants. Other trees mentioned with a high RFC were Curtisia dentata (Assegai), Strychnos henningsii (Panda's walking stick) and Olea europaea (Wild olive). Figure 4 shows the RFC values of the plants used (1) medicinally, (2) spiritually, (3) as building material and (4) as firewood in these separate categories. As expected, a wide range of plants are used for traditional medicines and for all tree species that are harvested from the forest, the bark is utilised; three of these species have been reported as being utilised as dens by the tree hyrax in the Pirie forest (Gaylard \& Kerley 2001; Figure 4a). A majority $(61 \%)$ of the respondents indicated that the products harvested were both for personal use and as a source of income, being sold either within their village or at local markets for plant medicines.

Of the respondents, $89 \%$ knew about the hyrax; $61 \%$ had heard the hyrax calling; $54 \%$ had seen it; and all eight hunters had hunted it. Of the respondents, $46 \%$ indicated

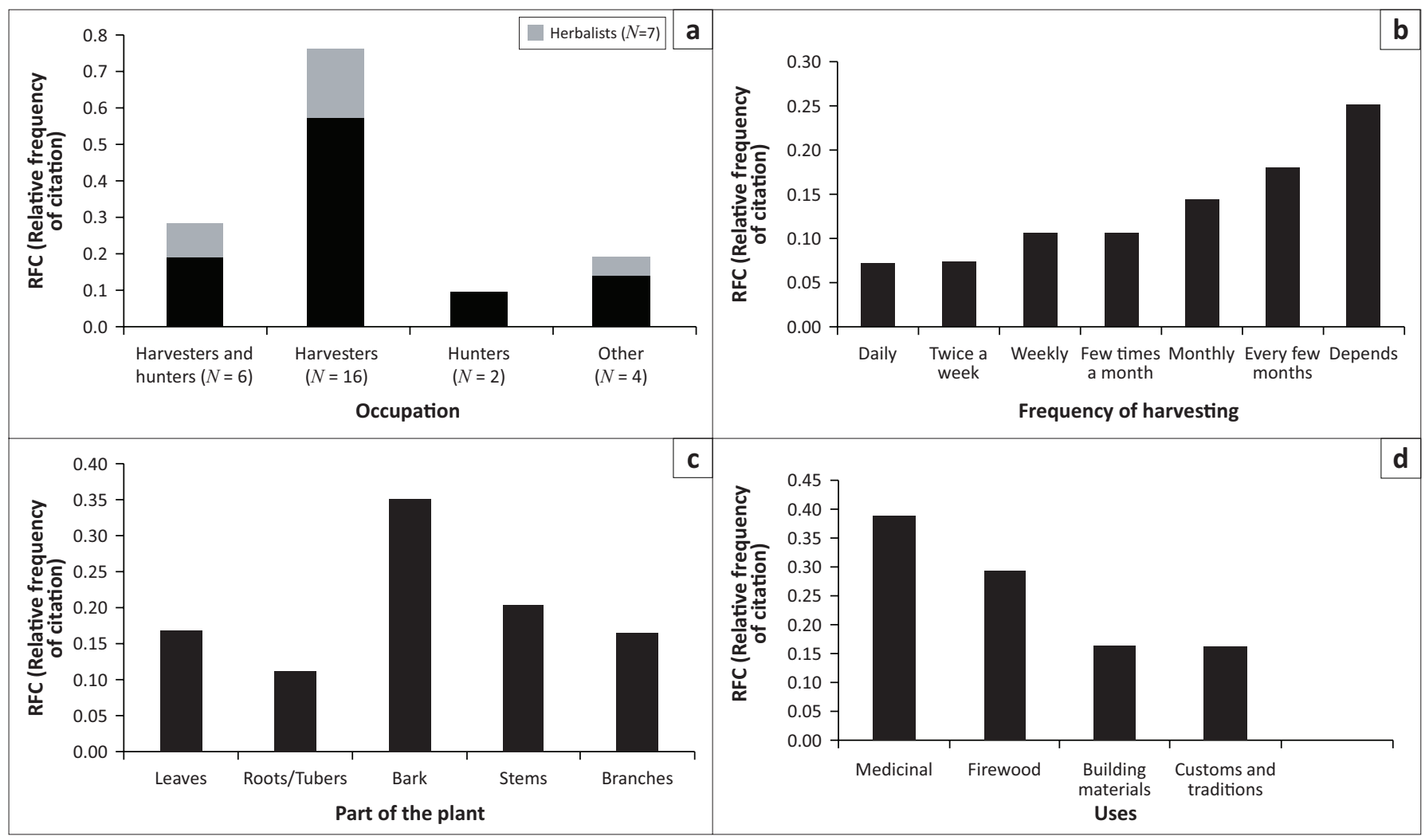

FIGURE 3: (a) The occupation of the participants, (b) the frequency of harvesting by participants, (c) the relative frequency of citation of the plant parts used by participants and (d) the RFC of the uses of the plants described by harvesters near the Pirie forest. 


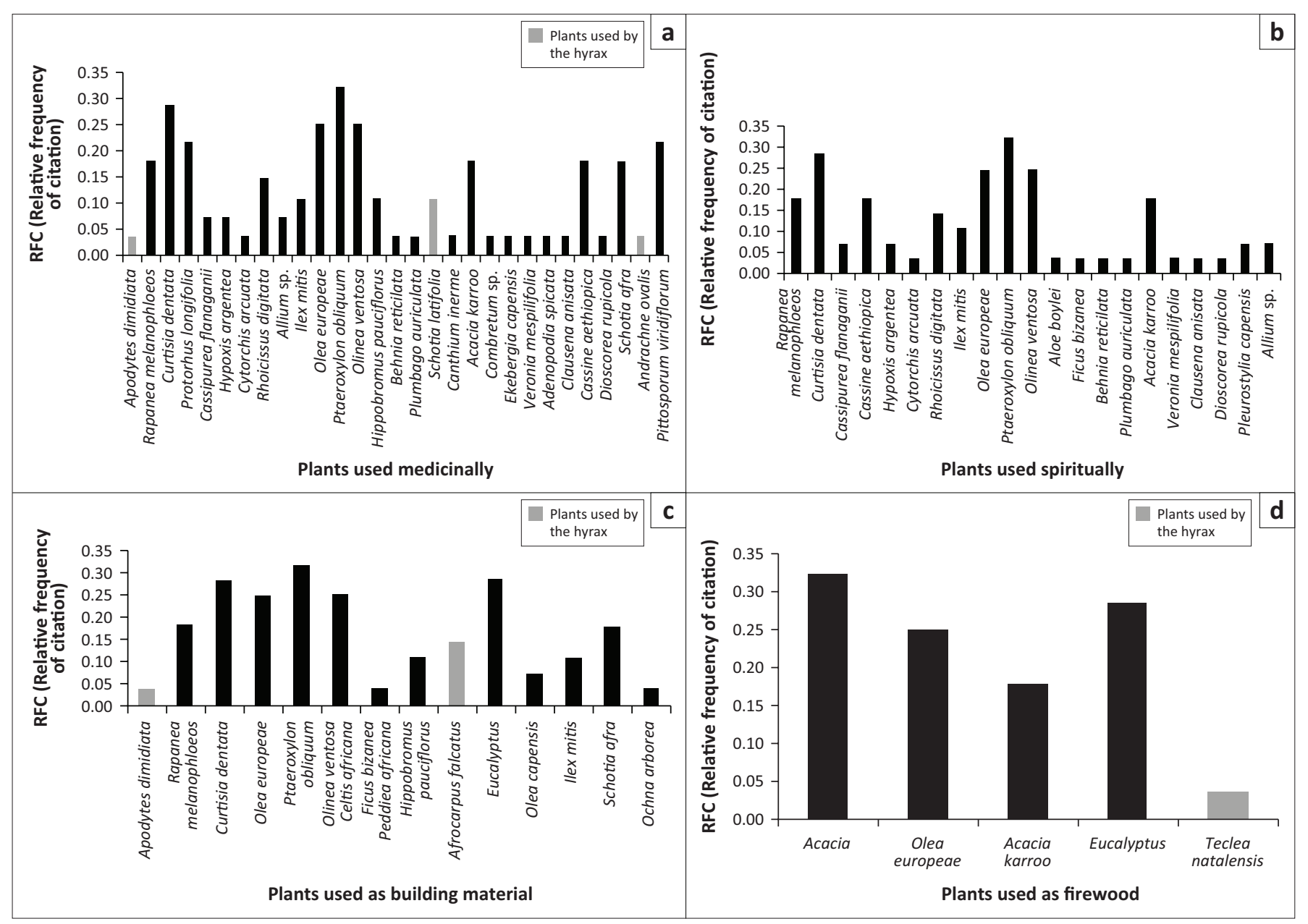

Source: Compiled by authors based on Gaylard, A. \& Kerley, G.I.H., 2001, 'Habitat assessment for a rare, arboreal forest mammal, the tree hyrax Dendrohyrax arboreus', African Journal of Ecology 39, 205-212. https://doi.org/10.1046/j.0141-6707.2000.301.x

FIGURE 4: The relative frequency of citation for plants used (a) medicinally, (b) spiritually, (c) as building materials and (d) as firewood by harvesters in the Pirie forest. Plant species used by the tree hyrax as dens are indicated in grey.

that the hyrax is hunted for meat; $12.5 \%$ of hunters reported hunting the hyrax for medicinal purposes and for entertainment, respectively. Those respondents familiar with tree hyraxes indicated that these animals were active at night and were 'difficult to catch as they live in tall trees'. Many respondents started to mimic the call of the tree hyrax during the interview, indicating that the isiXhosa word for it (umqha) when pronounced has a similar sound to its call. Those that had seen the tree hyrax likened it to imbila (rock dassie) but emphasised that it lives in trees and is shy. One of the respondents, who identified himself as a hunter, remarked that the hyrax is a 'tame, shy animal that is not intimidating and it does not really inspire one to try and hunt it' (Participant 24, Male, Matric, Unemployed, 18-29). Another conversation referred to the isiXhosa idiom Unyabe njengomqha which is translated as 'As shy as a tree hyrax' (Participant 19, Female, Tertiary education, Pensioned high school principal, 60-69). A traditional healer indicated that there is a general belief that eating the meat of the tree hyrax will make you tame, introverted and generally docile, but mentioned that it is not common to hunt the hyrax as it is difficult to catch them owing to their nocturnal habits. Another man had tried to hunt hyraxes but had never been successful. In general, those familiar with the hyrax also mentioned that it calls in the evenings, before proceeding to imitate the call, and noted that its call is very loud (and also peculiar).

To assess the importance of the forest and its likelihood as a resource in future generations, we were interested in knowing at what age villagers started to learn about the forest or use the forest, and whether they perceived the forest as important for future generations. Lastly, we wanted to understand whether they saw the forest as a renewable resource. All the participants indicated that their ancestors had utilised the forest and many of them indicated that they would want their descendants to continue the culture of utilising the forest, or at least understand the value of the forests in their lives. One of the respondents indicated that they would teach their children as it will 'restore and uphold the cultural heritage and traditions of the amaXhosa' (Participant 16, Male, Grade 7 or below, Unemployed, 40-49). It became apparent that linking the forest and its future regeneration is also important as 'ancestors are linked to nature and the forest is a refuge for their souls' (Participant 4, Male, Grade 7 or below, Pensioner, 50-59). The villagers regarded the forests as being renewable, and that it is renewable as some plants: 
re-sprout through roots and also some trees regenerate through seeds; and those animals reliant on trees for their habitat and food as a resource would thus be maintained in the future. (Participants 8, Female, Grade 7 or below, Unemployed, 50-59)

With regard to knowledge transmission pertaining to the hyrax and harvesting of plant material, $79 \%$ of the interviewees expressed the importance of future generations carrying on these traditions. They emphasised this as a way of staying connected with their ancestors. One of the respondents said: 'Although it is our heritage, we now live in a modern context and traditions are not always passed on. We want our children to know and appreciate our culture' (Participant 19, Female, Tertiary education, Pensioned high school principal, 60-69).

Our data illustrated that men mostly received knowledge from their fathers or grandfathers, whilst women mostly received knowledge from their mothers or grandmothers, and thus knowledge was transferred vertically, and mostly gender specifically. Some of the participants indicated that the sharing of knowledge with peers is also important. One man indicated that the tree hyrax is not only important medicinally but it is also safe for women to eat it 'as it does not interfere with their ability to bear children' (Participant 16, Male, Grade 7 or below, Unemployed, 40-49). Although they have no substantial uses for the tree hyrax, it was perceived as an important part of the general ecology of the forest. This was further echoed by those without children, who confirmed that being in the forest whether for hunting, harvesting and/or leisure allowed them to commune with nature, rejuvenating their spirits and essentially giving them a 'new life'. Many respondents indicated that they had started to visit the forest and to be taught how to use the forest from a young age (between the ages of 8 and 16).

\section{Ethical considerations}

Participation in the interviews was voluntary and the ethical guidelines of Stellenbosch University were followed. Ethical clearance for the interviews was obtained from the Departmental Ethical Clearance Committee (DESC) at the University of Stellenbosch (Reference number: DESC/ Opperman/May2015/1).

\section{Discussion}

Although five (S. latifolia, And. ovalis, Apo. dimidiata, A. falcatus, T. natalensis) of the six tree species used by the tree hyrax as dens in the Pirie forest (Gaylard \& Kerley 2001) were reported (Figure 2) as being harvested (out of a total of 42 reported harvested species), all five had low RFC values. Of these, S. latifolia and A. falcatus had the highest RFC values, (0.14 in each case). The other tree species had very low RFC values of 0.04 (Figure 2), suggesting that they were being harvested less. Searsia chirindensis was the only tree used by the hyrax (Gaylard \& Kerley 2001) which was not reported as being harvested. As the bark of $S$. latifolia is used medicinally (Dold \& Cocks 2012) and as A. falcatus is in addition commercially logged (Mpisekaya \& Kameni 2007), it may be worth investigating community harvesting levels of these tree species in more detail.

Of the 36 plant species reported in the diet of the tree hyrax in the Pirie forest (Gaylard \& Kerley 1997), only seven were mentioned as being harvested (RFC values in brackets): O. europaea (0.32), Hippobromus pauciflorus (False horsewood) (0.11), Pleurostylia capensis (Coffee pear), Behnia reticulata (Forest smilax), Olea capensis (Ironwood) (0.07), Apo. dimidiata and Ekebergia capensis (Cape ash) (0.04). However, as tree hyraxes eat leaves from a wide range of species, harvesting is unlikely to impact their foraging habits heavily. Disturbance relating to the harvesting of trees other than those it uses as dens or for foraging could conceivably be detrimental to the tree hyrax, owing to a loss of canopy cover. Topp-Jørgensen et al. (2008) emphasised how tree hyraxes preferred undisturbed forests with closed canopies, with the number of calling individuals being highest in undisturbed closed canopies. More open canopies thus lead to habitat unsuitability, as the hyrax uses arboreal pathways as a predator escape strategy.

With regard to hunting, none of the female participants and only a minority (8) of the 20 male participants reported to hunt or have hunted the hyrax during the course of their lives. Hunting of the hyrax that does take place is opportunistic and largely for recreational purposes (the experience of tasting hyrax meat). For subsistence, bush pigs (Potamochoerus larvatus) are hunted, but the time investment required to hunt the hyrax is not justified owing to its relatively small size and as it is not used for traditional purposes. In Xhosa culture, the tree hyrax is associated with being 'timid' and is often used to express perceptions being linked to having a docile personality embodied in the idiom that states 'unyabe ngathi utye umgha - you are as docile as if you ate a tree hyrax'. This saying may even dissuade many from actively hunting the tree hyrax. A study in the Mau forest of Kenya on the tree hyrax reported similar low levels of hunting (Milner 1994). In the Udzungwa Mountains in Tanzania (where the tree hyrax is found), bush meat comprises little of the meat intake of the locals, but when the local fauna is hunted larger fauna are preferred, provided they are available (Nielsen 2006).

Low income and educational levels explain the reliance of the communities on the forest as a source of additional income and for cultural practices, with them obtaining firewood, building material and medicines from the forest (Dold \& Cocks 2012). Most participants indicated that harvesting is both for the generation of income and for personal use. The fact that participants indicated that most of the natural material obtained is for medicinal purposes suggests the importance of traditional medicine in these communities (Figure 3d); it serves as the primary source of healthcare in the province (Dold \& Cocks 2012; Makunga, Philander \& Smith 2008).

Participants indicated that they mainly use the bark (Figure 3c), which could be problematic as in some trees 
ring-barking often leads to the death of the tree and thus extensive harvesting of bark may lead to a decrease in tree density (e.g. Delvaux, Sinsin \& Van Damme 2010). There were few indications of ring-barking in the Pirie forest (E.J.O., M.I.C., N.P.M. pers. obs., 13-17 July 2015), but this merits further investigation. Some of the respondents indicated that they were aware that forest guards were monitoring the practices of harvesting associated with the Pirie forest. The respondents also informed us that forest guards provided education about the forest ecosystem in an attempt to promote sustainable harvesting practices in the Pirie forest.

Regarding the frequency of harvesting, it is evident that villagers go out harvesting depending on when they need the material, with a low frequency of participants saying that they harvest daily (Figure 3b). Most participants reported harvesting between $1 \mathrm{~kg}$ and $25 \mathrm{~kg}$ per trip, which amounts to what a person is able to carry either in a rucksack or on their head. Some participants remarked that they harvest only as much as they need; others said that they harvested only pieces of bark. This can be in accordance with the theza load allowed in forests, provided that only dead or fallen trees are harvested and no cutting implements are employed. However, three participants declared taking more, with one mentioning $70 \mathrm{~kg}$, one $500 \mathrm{~kg}$ and one saying he takes a tractor load per month. The participant who reported $500 \mathrm{~kg}$ harvested dead trees (mainly used for kraals) and the one who indicated a tractor load felled the trees and sold them, although this comprised mainly the invasive species, Aca. mearnsii. This particular species was often the first species mentioned by respondents and this may be linked to the fact that harvesting alien invasives is not only legal but also actively promoted by nature conservation agencies.

The tree listed most was Acacia owing to its use as firewood, followed by P. obliquum, which is used medicinally, culturally and as building material. The latter is considered a sacred tree by the amaXhosa owing to it being symbolically linked to the ancestors (Dold \& Cocks 2012) and is currently classified as being of least concern according to the South African Red Data List (Raimondo et al. 2009). Other trees mentioned in high frequencies were $C$. dentata, Eucalyptus, O. europaea and S. henningsii. These plants also had the highest RFC values, indicating their importance in the community. Of these trees, $C$. dentata is used as building material as well as for medicinal and spiritual purposes (Dold \& Cocks 2012). For the continued ethnobotanical use of this particular tree, harvesting of $C$. dentata is of concern, as it has a 'near threatened' status according to the Red Data List (Raimondo et al. 2009) and thus the high levels of harvesting of this species are problematic. The extent of harvesting of this tree species needs to be monitored. Worthy of mention is the medicinal utilisation of Rapanea melanophloeos, Hypoxis hemerocallidea (African potato), Ilex mitis (Cape holly) and Cassipurea flanaganii (Cape Onionwood). These species, although having low RFC values (Figure 4), were all recorded in the medicinal plant trade and in addition $C$. flanaganii is listed as endangered, whilst $R$. melanophloeos, H. hemerocallidea and I. mitis are all listed as declining (Raimondo et al. 2009; Williams, Victor \& Crouch 2013). It is therefore important to place restrictions on trade of these species, which could be compensated for by utilising common species with the same active compounds. Furthermore, some of the respondents indicated that they are conservative in the quantities that they harvest for their personal subsistence but that gatherers and medicinal plant vendors from other areas or villages distant from Pirie harvest illegally at night and often in large quantities for the medicinal trade.

Villagers were aware of the risk of unsustainable utilisation of forest resources. All the participants had a high appraisal of the socio-psychological experiences linked to activities that take them into the forest, indicating that knowledge and utilisation of natural products collected from the forest is an important aspect of their cultural identity that should be continued by future generations.

Hunting that occurs is mainly opportunistic and is unlikely to have a significant impact on hyrax populations. The expanse of the forest is perceived to have undergone little change, but changes to the quality of the forest need monitoring as local communities and commercial activities may lead to ecosystem changes. Disturbances in the form of harvesting and hunting may have an effect on hyrax populations, as these activities could potentially alter the canopy, leading to a reduction in the capability of the hyrax to avoid natural predators. Although commercial harvesting in the forest has remained at a constant level since 2007 (Mpisekaya \& Kameni 2007), the impact of this harvesting on the hyrax population is unknown and should be monitored in future. Although labour intensive, this can be accomplished by monitoring den occupation by ascertaining the presence or absence of hyrax faeces in tree hollows, and the estimate of Gaylard (1994), using this technique, provides a baseline against which population changes can be measured.

\section{Conclusion}

Of the tree species used by the hyrax as dens in the Pirie forest, A. falcatus, S. latifolia, A. ovalis, T. natalensis and $A$. dimidiata are important resources for local communities. As these are harvested at relatively low levels, it is unlikely that current harvesting has a large impact on the tree hyrax. We recommend ongoing monitoring of the Pirie forest tree hyrax population in order to ascertain the impact of both commercial and community harvesting over the past quarter century.

\section{Acknowledgements}

We would like to thank the interviewees from the communities surrounding the Pirie forest and the herbal vendors interviewed in King Williams Town. Mr Mzonke 'Ronnie' Makhahla and Mr Khanyisa Mzamo are thanked for their assistance and Ms Bukiwe Mzamo is thanked for translating the questionnaire into isiXhosa. This study was funded by a 
bursary to E.J.O. from the SASOL Inzalo Foundation; running expenses were provided by grants (96257) to M.I.C. and to N.P.M. (76555) from the National Research Foundation of South Africa.

\section{Competing interests}

The authors declare that they have no financial or personal relationships that may have inappropriately influenced them in writing this article.

\section{Authors' contributions}

E.J.O. and N.P.M. conducted interviews, whereas E.J.O. analysed the data. All the authors wrote the manuscript.

\section{References}

Brown, K., 2003, 'Trees, forests and communities': Some historiographical approaches to environmental history on Africa', Area 35(4), 343-356.

Butynski, T., Hoeck, H. \& De Jong, Y.A., 2015, Dendrohyrax arboreus. The IUCN Red List of Threatened Species. 2015: e.T6409A21282806, Intrenational Union for the Conservation of Nature, Cambridge, UK. https://doi.org/10.2305/IUCN.UK.20152.RLTS.T6409A21282806.en

Castley, J.G. \& Kerley, G.I.H., 1996, 'The paradox of forest conservation in South Africa', Forest Ecology and Management 85, 35-46. https://doi.org/10.1016/S0378$1127(96) 03748-6$

Cooper, T.J.G., Wannenburgh, A.M. \& Cherry, M.I., 2017, 'Atlas data indicate fores dependent bird species declines in South Africa', Bird Conservation International 27, 337-354. https://doi.org/10.1017/S095927091600040X

Cunningham, A.B. \& Davis, C.W., 1997, 'Human use of plants', in R.M. Cowling, D.M. Richardson \& S.M. Pierce (eds.), Vegetation of Southern Africa, pp. 477-501, Cambridge University Press, Cambridge, UK.

Delvaux, C., Sinsin, B. \& Van Damme, P., 2010, 'Impact of season, stem diameter and intensity of debarking on survival and bark re-growth pattern of medicinal tree species, Benin, West Africa', Biological Conservation 143, 2664-2671. https://doi. org $/ 10.1016 / \mathrm{j}$.biocon.2010.07.009

Dold, A.P. \& Cocks, M.L., 1999, 'Preliminary list of Xhosa plant names from Eastern Cape, South Africa', Bothalia 29, 267-292. https://doi.org/10.4102/abc.v29i2.601

Dold, A.P. \& Cocks, M.L., 2012, Voices from the forest: Celebrating nature and culture in Xhosaland, Craft Print International Ltd., Auckland Park, South Africa.

Gaylard, A., 1994, 'The tree hyrax (Dendrohyrax arboreus) as a rare forest species: Habitat and diet', MSc thesis, University of Port Elizabeth.

Gaylard, A. \& Kerley, G.I.H., 1997, 'Diet of tree hyraxes Dendrohyrax arboreus (Hyracoidea: Procaviidae) in the Eastern Cape South Africa', Journal of Mammalogy 78, 213-221. https://doi.org/10.2307/1382654

Gaylard, A. \& Kerley, G.I.H., 2001, 'Habitat assessment for a rare, arboreal forest mammal, the tree hyrax Dendrohyrax arboreus', African Journal of Ecology 39, 205-212. https://doi.org/10.1046/j.0141-6707.2000.301.x
Gaylard, A., Venter, J., Ehlers-Smith, Y. \& Child, M.F., 2016, 'A conservation assessment of Dendrohyrax arboreus', in M.F. Child, L. Roxburgh, E. Do Linh San, D. Raimondo \& H.T. Davies-Mostert (eds.), The red list of mammals of South Africa, Swaziland and Lesotho, South African National Biodiversity Institute and Endangered and Lesotho, South African National Biodiversity Institute and Endangered Wildlife Trust, South Africa, viewed 22 June 2017, from https://www.ewt.org.za/
Reddata/pdf/Hyracoidea/2016\%20Mammal\%20Red\%20List_Dendrohyrax\%20 Reddata/pdf/Hyracc
arboreus_EN.pdf

Google Earth 7.1.1.1888, 2013, Pirie Main Forest Reserve $32^{\circ} 46^{\prime} 59^{\prime \prime} \mathrm{S}, 27^{\circ} 13^{\prime} \mathrm{O}^{\prime \prime} \mathrm{E}$ Elevation: 686 m, viewed 04 March 2015, from https://earth.google.com/web/@$32.84609917,27.47770818,506.94577214 a, 77550.7433243 \mathrm{~d}, 35 \mathrm{y}, 0.00000009 \mathrm{~h}, 2$ $62787946 \mathrm{t},-0 \mathrm{r} /$ data=CksaSRJDCiUweDFINjZIMTE2ZDVkOWQ3YjU6MHg5ZTF MWEONjQzNDRmNThmGR5CpsaVgkDAIY50BkZe3DtAKghOZXcgUmVzdBgBIAE

Greyling, T. \& Huntley, B.J., 1984, Directory of Southern African conservation areas, South African National Scientific Progress Report No. 98, Council for Scientific and Industrial Research, Pretoria, $311 \mathrm{p}$.

Lawes, M.J., Mealin, P.E. \& Piper, S.E., 2000, 'Patch occupancy and potential metapopulation dynamics of three forest mammals in fragmented Afromontane forests in South Africa', Conservation Biology 14, 1088-1098. https://doi. org/10.1046/j.1523-1739.2000.99120.x

Lawes, M.J., Midgley, J.J. \& Chapman, C.A., 2004, 'South Africa's forests: The ecology and sustainable use of indigenous timber resources', in M.J. Lawes, H.A.C. Eeley, C.M. Shackleton \& B.G.S. Geach (eds.), Indigenous forests and woodlands in South Africa: Policy, people and practice, pp. 31-75, University of KwaZulu-Natal Press, Scottsville.

Low, A.B. \& Rebelo, A.G., 1996, Vegetation of South Africa, Lesotho and Swaziland, Department of Environmental Affairs and Tourism, Pretoria.

Makunga, N.M., Philander, L.E. \& Smith, M., 2008, 'Current perspectives on an emerging formal natural products sector in South Africa', Journal of Ethnopharmacology 119, 365-375. https://doi.org/10.1016/j.jep.2008.07.020

Milner, J., 1994, 'Relationships between the forest-dwelling people of South-West Mau and tree hyrax, Dendrohyrax arboreus', Journal of East African Natural
History 83, 17-29. https://doi.org/10.2982/0012-8317(1994)83[17:RBTFDP]2. History

Mpisekaya, S.R. \& Kameni, C., 2007, Amatole forest yellowwood harvesting levels, Department of Water Affairs and Forestry, Pretoria.

Nielsen, M.R., 2006, 'Importance, cause and effect of bushmeat hunting in the Udzungwa Mountains, Tanzania: Implications for community based wildlife management', Biological Conservation 128, 509-516. https://doi.org/10.1016/j. management', Biologic

Raimondo, D., Von Staden, L., Foden, W., Victor, J.E., Helme, N.A., Turner, R.C. et al. (eds.), 2009, 'Red list of South African plants 2009', in Strelitzia, p. 25, South African National Biodiversity Institute, Pretoria.

Samoisy, A.K. \& Mahomoodally, M.F., 2015, 'Ethnopharmacological analysis of medicinal plants used against non-communicable diseases in Rodrigues Island, Indian Ocean', Journal of Ethnopharmacology 173, 20-38. https://doi.org/ 10.1016/j.jep.2015.06.036

Topp-Jørgensen, J.E., Marshall, A.R., Brink, H. \& Pederson, H.B., 2008, 'Quantifying the response of tree hyraxes (Dendrohyrax validus) to human disturbance in the Udzungwa Mountains, Tanzania', Tropical Conservation Science 1, 63-74. https:// doi.org/10.1177/194008290800100106

Von Maltitz, G., Mucina, L., Geldenhuys, C., Lawes, M., Eeley, H. \& Adie, H., 2003, Classification System for South African Indigenous Forests: An objective classification for the Department of Water Affairs and Forestry, Environmental Report: 1-284, Council for Scientific and Industrial Research, Pretoria.

Williams, V.L., Victor, J.E. \& Crouch, N.R., 2013, 'Red listed medicinal plants of South Africa: Status, trends and assessment challenges', South African Journal of Botany 86, 23-25. https://doi.org/10.1016/j.sajb.2013.01.006 


\section{Appendix 1 \\ Questionnaire}

Gender:

Age:

Education:

Birthplace:

Race:

Income per month:
[Male] [Female]

[18-29] [30-39] [40-49] [50-59] [60-69] [70+]

[Grade 7 or below] [Grade 10] [Matric] [Bachelors] [More]

[African] [Mixed race] [White] [Indian or Asian] [Other]

[Less than R500] [R500-R1000] [R1000-R3000] [R3000-R10 000] [More than R10 000]

Occupation:

Do you harvest in the Pirie forest? [Yes] [No]

Which trees do you harvest?

What part of the tree do you harvest?

How often do you harvest?

[Yearly] [Twice a year] [Every few months] [Monthly]

[Twice a month] [Weekly] [Daily]

How much do you harvest at a time?

What do you use the products you harvest for?

Are the products you get from harvesting only for personal use or do you sell them as well?

$$
\text { [Sell them] [Personal use] [Both] }
$$

Since what age have you been harvesting in the forest?

Who taught you to harvest and use the product like that?

Do you see the forest as a resource that can be renewed?

[Yes] [No]

What do you know about the tree hyrax present in the forest?

[Yes] [No]

Do you hear the tree hyrax in the forest?

Have you ever seen the tree hyrax and do you still see them around?

Do you hunt the tree hyrax or know of someone who does?

[Yes] [No]

If you answered 'yes' to the previous question, what do you and/or they hunt the tree hyrax for?

Do you know anyone else I can talk to about this?

Thank you so much for your time and patience. I will come back to you with the results of this survey. 